\title{
Effects of wine-cap Stropharia cultivation on soil nutrients and bacterial communities in forestlands of northern China
}

\author{
Sai Gong ${ }^{1}$, Chen Chen ${ }^{1}$, Jingxian Zhu ${ }^{1}{ }^{\text {, Guangyao }} \mathbf{Q i}{ }^{1}$, Shuxia Jiang ${ }^{\text {Corresp. }} 1$ \\ ${ }^{1}$ College of Plant Protection; Shandong Province Key Laboratory of Agricultural Microbiology; Engineering Research Centre of Forest Pest Management of \\ Shandong Province, Shandong Agricultural University, Taian, Shandong, China \\ Corresponding Author: Shuxia Jiang \\ Email address: jsx6206@163.com
}

Background. Cultivating the wine-cap mushroom (Stropharia rugosoannulata) on forestland has become popular in China. However, the effects of wine-cap Stropharia cultivation on soil nutrients and bacterial communities are poorly understood.

Methods. We employed chemical analyses and high-throughput sequencing to determine the impact of cultivating the wine-cap Stropharia on soil nutrients and bacterial communities of forestland.

Results. Cultivation regimes of Stropharia on forestland resulted in consistent increases of soil organic matter (OM) and available phosphorus (AP) content. Among the cultivation regimes, the greatest soil nutrient contents were found in the one-year interval cultivation regime, and the lowest total $\mathrm{N}$ and alkaline hydrolysable $\mathrm{N}$ contents were observed in the current-year cultivation regime. No significant differences were observed in alpha diversity among all cultivation regimes. Specific soil bacterial groups, such as Acidobacteria, increased in abundance after cultivation of Stropharia rugosoannulata.

Discussion. Given the numerous positive effects exerted by OM on soil physical and chemical properties, and the consistent increase in OM content for all cultivation regimes, we suggest that mushroom cultivation is beneficial to forest soil nutrient conditions through increasing OM content. Based on the fact that the one-year interval cultivation regime had the highest soil nutrient content as compared with other cultivation regimes, we recommend this regime for application in farming practice. The spent mushroom compost appeared to be more influential than the hyphae of $S$. rugosoannulata on the soil nutrients and bacterial communities; however, this requires further study. This research provides insight into understanding the effects of mushroom cultivation on the forest soil ecosystem and suggests a relevant cultivation strategy that reduces its negative impacts. boif 


\section{Effects of Wine-cap Stropharia Cultivation on Soil Nutrients}

\section{2 and Bacterial Communities in Forestlands of Northern China}

3 Sai Gong ${ }^{1}$, Chen Chen $^{1}$, Jingxian $\mathrm{Zhu}^{1}$, Guangyao $\mathrm{Qi}^{1}$, Shuxia Jiang ${ }^{1}$

$4{ }^{1}$ College of Plant Protection, Shandong Agricultural University; Shandong Province Key Laboratory of

5 Agricultural Microbiology; Engineering Research Centre of Forest Pest Management of Shandong

6 Province; Taian 271018, China

7

8 Corresponding Author:

9 Shuxia Jiang ${ }^{1}$

10 Daizong Road No.61, Taian, Shandong, 271018, China

11 Email address: jsx6206@163.com

12

13

14

15

16

17

18 


\section{Abstract}

25 Background. Cultivating the wine-cap mushroom (Stropharia rugosoannulata) on forestland

26 has become popular in China. However, the effects of wine-cap Stropharia cultivation on soil

27 nutrients and bacterial communities are poorly understood.

28 Methods. We employed chemical analyses and high-throughput sequencing to determine the

29 impact of cultivating the wine-cap Stropharia on soil nutrients and bacterial communities of

30 forestland.

31 Results. Cultivation regimes of Stropharia on forestland resulted in consistent increases of soil

32 organic matter (OM) and available phosphorus (AP) content. Among the cultivation regimes, the

33 greatest soil nutrient contents were found in the one-year interval cultivation regime, and the

34 lowest total $\mathrm{N}$ and alkaline hydrolysable $\mathrm{N}$ contents were observed in the current-year cultivation

35 regime. No significant differences were observed in alpha diversity among all cultivation

36 regimes. Specific soil bacterial groups, such as Acidobacteria, increased in abundance after

37 cultivation of Stropharia rugosoannulata.

38 Discussion. Given the numerous positive effects exerted by OM on soil physical and chemical

39 properties, and the consistent increase in OM content for all cultivation regimes, we suggest that

40 mushroom cultivation is beneficial to forest soil nutrient conditions through increasing OM

41 content. Based on the fact that the one-year interval cultivation regime had the highest soil

42 nutrient content as compared with other cultivation regimes, we recommend this regime for 
43 application in farming practice. The spent mushroom compost appeared to be more influential

44 than the hyphae of S. rugosoannulata on the soil nutrients and bacterial communities; however,

45 this requires further study. This research provides insight into understanding the effects of

46 mushroom cultivation on the forest soil ecosystem and suggests a relevant cultivation strategy

47 that reduces its negative impacts.

\section{Introduction}

49 The wine-cap Stropharia mushroom (Stropharia rugosoannulata Farlow ex. Murrill) is one of

50 the top ten mushrooms traded internationally and is recommended by the UN Food and

51 Agriculture Organization for export to developing countries (Murrill 1922; Hawksworth et al.

52 1996). This mushroom is sciophilous and can be cultivated with different kinds of raw materials,

53 such as straw, sawdust, rice husk and corncobs (CUCEDH 2013; Domondon and Poppe 2000;

54 Gong et al. 2016). It is easy to cultivate and can reach a high yield with extensive management.

55 These features make $S$. rugosoannulata suitable for under-forest cultivation. In practice, this

56 mushroom has been cultivated in large gardens with trees and shrubs (Domondon and Poppe

57 2000) and under hardwood shade (Bruhn et al. 2010). Many experiments have been carried out

58 to increase mushroom production (Bonenfant-Magne' et al. 2000; Domondon et al. 2004; Bruhn

59 et al. 2010; Zeng 2013), which have enabled the large-scale cultivation of S. rugosoannulata.

60 Cultivating mushrooms in forestlands, including under the shade of nursery stocks, has

61 become popular in China. This kind of mushroom cultivation can efficiently use the large

62 expanses of space under nursery stocks. Meanwhile, the straw by-products, which are usually 
63 incinerated or discarded in the field (Lu et al. 2018), can be consumed by the mushrooms,

64 thereby reducing waste and air pollution. Due to this, the Chinese government has encouraged

65 the cultivation of economically valuable mushrooms in forestland. Thus, the wine-cap

66 Stropharia is cultivated under the forest as such a kind of mushroom in several Chinese

67 provinces, including Shandong, Fujian (Zeng 2013) and Yunnan (Yang et al. 2015).

68 In China, nursery soil has suffered from improper managements, including flood irrigation

69 and excessive inputs of synthetic nitrogen fertilizer. Additionally, topsoil is removed with

70 seedings and nursery stock transactions each year. All these can cause soil erosion, degradation

71 (Wang et al. 2004), pollution (Dissanayake and Rajapaksha 2013) and acidification (Conyers et

72 al. 2011; Geng et al. 2016). Fortunately, the importance of these problems has now become

73 apparent, and several attempts have been made to improve soil conditions (Chadwick et al. 2015;

74 Zheng et al. 2016; Sihi et al. 2017). In several studies, the residual compost waste generated by

75 the mushroom production, i.e. spent mushroom compost, is used in soil bioremediation to

76 improve soil aeration, maintain soil structure (Kadiri and Mustapha 2010), balance soil nutrient

77 (Uzun 2004; Jonathan et al. 2011), and increase soil biological activity (Li et al. 2012). Growing

78 mushrooms under nursey stocks can be a good alternative, as a considerable amount of spent

79 mushroom compost will be left in the soil after mushroom harvesting. However, there is

80 currently very limited understanding of the effects on soil nutrients that are caused by mushroom

81 cultivation. Additionally, how mushroom cultivation will influence microbial community

82 composition is also worthy of attention, given that the hyphae of these mushrooms can select 
83 certain bacterial taxa in the soil (Nazir et al. 2010). Finally, there is concern that the cultivation

84 of S. rugosoannulata on forestland might lead to soil nutrient loss (Socolow 1999). In this study,

85 we investigated how different cultivation regimes affect the sustainable development of $S$.

86 rugosoannulata stocks under nursery stock shade.

87 Specifically, we cultivated S. rugosoannulata under nursery stocks in Liying (Jining,

88 Shandong, China), one of the largest centres for seedling production in China. We used four

89 cultivation regimes, based on common methods: ( $\mathrm{i}$ ) fallow for one year after prior cultivation

90 regime (Y010), ( ii ) two years of continuous cultivation regime (Y011), (iii) current-year

91 cultivation regime (Y001), (iv ) one-year interval cultivation regime (Y101), to test the effects of

92 growing S. rugosoannulata on influencing soil nutrients and soil microbial community

93 composition.

\section{Materials and Methods}

95 Experimental site

96 The experimental forestland was an area of $20 \times 150 \mathrm{~m}$, located in Liying Town, Jining City,

97 Shandong Province ( $116^{\circ} 37^{\prime} \mathrm{E}, 35^{\circ} 30^{\prime} \mathrm{N}, 43 \mathrm{~m}$ above sea level). The nursery stock is made up by

98 7- to 10-year-old trees of horse chestnut (Aesculus chinensis Bunge), which were planted with 2

$99 \mathrm{~m}$ spaces between plants in rows and $5 \mathrm{~m}$ between rows to achieve a canopy density of 0.7 . This

100 location is considered a warm temperate, semi-humid monsoon climate characterized by hot,

101 rainy summers and cold, dry winters, with an annual average temperature of $13.2-14.1{ }^{\circ} \mathrm{C}$. The

102 highest temperature in July exceeded $27^{\circ} \mathrm{C}$, and the annual average temperatures above $10{ }^{\circ} \mathrm{C}$ 
103 accumulated to $4060.7^{\circ} \mathrm{C}$ (growing degree days). The annual precipitation is $650-700 \mathrm{~mm}$, with

104 rainfall from May to August accounting for more than $65 \%$ of the total rainfall for the whole

105 year. The soil type was non-calcareous cinnamon tide with a clay loam texture. All these data

106 were obtained from the Jining Soil and Fertilizer Workstations, China (1990).

107 Sample plots and S. rugosoannulata cultivation

108 The experimental forestland was divided into five $20 \times 30 \mathrm{~m}$ grids, which were marked as Y000,

109 Y010, Y011, Y001, and Y101 respectively. Among them, Y010, Y011, Y001, and Y101 were

110 used for mushroom cultivation with different regimes, and each of them was divided into three,

$11110 \times 20 \mathrm{~m}$ plots for independent replicates; Y000 was used as a no-cultivation control. The

112 cultivation year of each grid is shown in Table 1.

113 The cultivation of S. rugosoannulata began in 2013 and was performed every November as

114 described by Gong et al. (2016). The basic materials included 48.9\% rice husk, 30\% corncobs

115 crushed into particles with a diameter of $0.5 \mathrm{~cm}$ to $1 \mathrm{~cm}, 20 \%$ sawdust, which was a mixture that

116 contained a variety of hardwood chips, $1 \%$ soil acquired from each plot before cultivation and

$1170.1 \%$ lime. These materials were mixed, stacking fermentation was performed, and then

118 distributed onto the sample plots between the plant rows with a thickness of approximately 25

$119 \mathrm{~cm}$. The $S$. rugosoannulata spawn was divided into blocks of approximately $3 \mathrm{~cm}$ in length and

120 inoculated into the fermented material using superimposed square planting. Then, $3 \mathrm{~cm}$ of the

121 forest surface soil was sprinkled onto the surface of the fungal bed. The fungal bed was vented

122 and kept moist by a 2-3 cm cover of straw under black plastic film. A micro-spray system was 
123 installed in each plot, and the ditch between the cultivation beds drained into a stagnant water

124 well. By April of the next year, fruiting had begun, and by late June, the harvest was complete.

125 The soil was subjected to rotary tillage in November, i.e., the material rotting stage (MRS).

126 Sample collection and measurements of soil properties

127 A five-point sampling method was used to collect soil samples in October 2016. The surface

128 organic materials of Y011, Y001, and Y101, and $1 \mathrm{~cm}$ of the surface soil of Y000 and Y010

129 were removed to distinguish the effect of the raw organic materials added from the mushroom

130 cultivation. Five soil cores $(5 \mathrm{~cm}$ diameter $)$ were collected from each plot with a depth of $30 \mathrm{~cm}$,

131 fully pooled and then sifted using a 2-mm sieve. Subsequently, each soil sample was divided

132 evenly into two portions: one was air dried and used for soil nutrient measurements, and the

133 other was stored at $-20^{\circ} \mathrm{C}$ before soil DNA extraction.

134 The soil properties were measured in the Shandong Provincial Key Laboratory of Soil

135 Erosion and Ecological Restoration (Tai'an, Shandong, China). The soil organic matter (OM)

136 content was determined with the potassium dichromate external heating method (Ciavatta et al.

137 1991). The total nitrogen (TN) content was determined by the dichromate oxidization method

138 (Bremner 1965). The total phosphorus (TP) content was determined by molybdenum-blue

139 colorimetry after digestion by HF-HClO4 (Jackson 1958). The alkaline hydrolysable nitrogen

140 (AN) content was determined using the alkaline-hydrolysable diffusion method (Xiong et al.

141 2008). The available phosphorus (AP) was extracted with sodium bicarbonate and determined

142 using the molybdenum-blue method (Olsen 1954). The available potassium (AK) was extracted 
143 by ammonium acetate and then determined by flame photometry (Carson 1980). The soil pH was

144 determined according to the international standard with a soil/water ratio of 1:5 (ISO 10390:

145 2005). The soil field capacity (FC) was measured using the laboratory Wilcox method (Duan et

146 al. 2010).

147 Soil DNA extraction and polymerase chain reaction (PCR) amplification

148 The hexadecyl trimethyl ammonium bromide (CTAB) method was used for the soil DNA

149 extraction (Zhou et al. 1996), and the purity and concentration of genomic DNA was monitored

150 by $1 \%$ agarose gel electrophoresis. DNA was diluted to $1 \mathrm{ng} / \mu \mathrm{L}$ using sterile water for the PCR.

151 The forward specific primer 515F (5'-GTGCCAGCMGCCGCGGTAA-3') (Turner et al. 1999)

152 and reverse specific primer 907R (5'-CCGTCAATTCMTTTRAGTTT-3') (Lane et al. 1991)

153 were employed to amplify the V4-V5 region of 16S RNA. PCR-based amplifications were

154 performed using Phusion ${ }^{\circledR}$ High-Fidelity PCR Master Mix with GC Buffer and high-fidelity

155 DNA polymerase (New England Biolabs, USA) following an amplification programme of 1

156 cycle at $98{ }^{\circ} \mathrm{C}$ for $1 \mathrm{~min}, 30$ cycles composed of three steps for each cycle $\left(98{ }^{\circ} \mathrm{C}\right.$ for $10 \mathrm{~s}, 50{ }^{\circ} \mathrm{C}$

157 for $30 \mathrm{~s}$, and $72{ }^{\circ} \mathrm{C}$ for $30 \mathrm{~s}$ ), and a final elongation step of $72{ }^{\circ} \mathrm{C}$ for $5 \mathrm{~min}$.

158 Equal volumes of $1 \mathrm{X}$ loading buffer (containing SYBR green) and PCR products were

159 mixed and electrophoresed on a $2 \%$ agarose gel. Samples with bright main bands between 400

160 and $450 \mathrm{bp}$ were selected for further experimentation. The PCR products were mixed in

161 equidensity ratios and then purified with a Qiagen Gel Extraction Kit (Qiagen, Germany). The

162 library was constructed using TruSeq ${ }^{\circledR}$ DNA PCR-Free Sample Preparation Kit (Illumina, 
163 USA), and the library quality was assessed on the Qubit@2.0 Fluorometer (Thermo Scientific)

164 and Agilent Bioanalyzer 2100 systems. The library was sequenced on an Illumina HiSeq 2500

165 platform at Novogene Bioinformatics Technology Co., Ltd, Beijing, China., and 250 bp paired-

166 end reads were generated. All paired-end reads were deposited in Sequence Read Archive

167 (SRA), BioProject: PRJNA453134.

168 Bioinformatic analysis

169 Paired-end reads were assigned to samples based on their unique barcodes and truncated by

170 trimming the barcode and primer sequences. After that, paired-end reads were merged using

171 FLASH (V1.2.7; Magoč et al. 2011) to obtain raw tags. The raw tags were then subjected to

172 quality filtering using QIIME V1.7.0 (Caporaso et al. 2010) to obtain high-quality clean tags

173 (Bokulich et al. 2013). Default settings ( $\mathrm{r}=3 \mathrm{p}=0.75$ total read length; $\mathrm{q}=3 ; \mathrm{n}=0$; Sun et al. 2014)

174 was used for quality filtering. These clean tags were compared with the reference database (Gold

175 database, http://drive5.com/uchime/uchime download.html) using the UCHIME algorithm

176 (Edgar et al. 2011) to detect and remove chimaera sequences (Haas et al. 2011). Thus, we

177 obtained effective tags. Uparse software (v7.0.1001; Edgar 2013) was used to assign sequences

178 with more than $97 \%$ similarity to an operational taxonomic unit (OTU). Representative

179 sequences that showed the highest frequency for each OTU were screened for further taxonomic

180 assignment. The Mothur method with a threshold of 0.8-1 was selected in QIIME (Version

181 1.7.0), and the SSU rRNA database (Quast et al. 2013) in SILVA (Wang et al. 2007) was used

182 for taxonomic assignment. To obtain the phylogenetic relationships among different OTUs, 
183 multiple sequence alignments were conducted using MUSCLE software (Version 3.8.31; Edgar

184 2004). The phylogenetic tree for each sample plot was visualized using GraPhlAn (Asnicar et al. 185 2015).

186 The OTU abundance data were rarefied using a standard sequence number corresponding to

187 the sample with the fewest sequences. Subsequent analyses of the alpha diversity and beta

188 diversity were performed based on the rarefied output data. The alpha diversity indices,

189 including Good's coverage estimator and the Shannon and Simpson diversity indices, were

190 calculated using QIIME (Version 1.7.0). The differences in taxonomic composition were

191 evaluated using a beta diversity analysis. The methods of principal component analysis (PCA),

192 principal co-ordinates analysis (PCoA) and non-metric multi-dimensional scaling (NMDS) were

193 used to illustrate the clustering of different samples. PCA was calculated in the R packages

194 FactoMineR (Lê et al. 2008) and ggplot2 packages (Wickham et al. 2010), and the Hellinger

195 transformation method (Rao 1995) was used for PCA. PCoA of the weighted and unweighted

196 UniFrac distances was calculated in the R package "ape” (Lozupone and Knight, 2005). An

197 NMDS of the weighted and unweighted UniFrac distances was calculated according to Peck

198 (2010). A canonical correspondence analysis (CCA) calculated using the R package "vegan"

199 (Oksanen et al. 2007) was used to visualize the relationship between edaphic factors and the

200 bacterial community structure in each sample plot. Prior to performing the CCA, we filtered out

201 the intercorrelated environmental factors that affected sample distribution by using a variance

202 inflation factor (VIF) analysis (Gross et al. 2003). 
Statistical analysis

204 The soil chemical concentration, dominant taxa and alpha diversity indices were measured, and a

205 one-way analysis of variance (ANOVA) was performed to determine whether differences existed

206 among treatment means at a significance level of $\alpha=0.05$. Multiple comparisons were conducted

207 for significant effects using the Tukey's test at $\alpha=0.05$, and FDR of Benjamini-Hochberg

208 (Benjamini and Hochberg 1995) was used for Tukey’s test. These statistical analyses were

209 implemented using the Statistical Program for Social Sciences SPSS (Version 22; IBM, USA).

210 The linear discriminant analysis (LDA) effect size (LEfSe) (Segata et al. 2011) was used to

211 identify significantly different taxa among groups using the LEfSe software with a default LDA

212 score value of 4. An analysis of molecular variance (AMOVA, Excoffier et al. 1992), analysis of

213 similarities (ANOSIM, Clarke 1993) and permutational multivariate analysis of variance

214 (PERMANOVA or ADONIS, Anderson 2001) was used to determine differences in the

215 microbial community structure between the groups using the amova function in Mothur software

216 (https://www.mothur.org). Correlations among edaphic factors with estimated diversity levels

217 were tested for significance via Spearman's correlations (Algina et al. 1999) performed in R

218 (Version 2.15.3).

219 Results

220 Soil properties

221 As shown in Table 2, the cultivation of S. rugosoannulata in forestland changed the soil field

222 capacity, $\mathrm{pH}$, organic matter, total nitrogen, total phosphorus, alkaline hydrolysable nitrogen, 
223 available phosphorus and available potassium contents. The ANOVA showed that the soil

224 organic matter and available phosphorus increased significantly in all cultivating regimes of $S$.

225 rugosoannulata compared with the no-cultivation control. The soil nutrient concentrations in the

226 one-year interval cultivation regime were the highest among all grids. Additionally, the soil total

227 phosphorus and alkaline hydrolysable nitrogen in the fallow for one year after prior cultivation

228 regime, the soil total phosphorus, alkaline hydrolysable nitrogen, and available potassium in the

229 two years of continuous cultivation regime and the soil total nitrogen and alkaline hydrolysable

230 nitrogen in the current-year cultivation regime decreased significantly compared with those of

231 the control. In addition, the soil field capacity and $\mathrm{pH}$ in all cultivating regimes were not

232 significantly changed $(P<0.05)$.

233 Bacterial community composition

234 After removing potential chimaeras, a total of 1,127,888 high-quality V4-V5 16S rDNA

235 sequences were analysed across the 5 grids. These sequences were assigned to 8,751 OTUs. The

236 number of OTUs in the grids ranged from 4,756 to 5,011 (Table S1).

237 The phylogenetic relationship of different OTUs of each sample was illustrated in Figure S3-

238 17. The top ten most abundant phyla represented $94 \%$ of the sequences (Fig. 1a), of which,

239 Proteobacteria and Acidobacteria were the most dominant phyla in all groups, representing 55-

$24061 \%$ of the total sequences. Among them, only Acidobacteria, Planctomycetes and

241 Gemmatimonadetes showed significant changes in relative abundance between forestlands with

242 one of the cultivation regimes and the no-cultivation control (Fig. 1a, Table S2). Acidobacteria in 
243 the current-year cultivation regime was the most abundant, and was significantly more abundant

244 than in the control. The abundance of Planctomycetes in forestland with cultivation was greater

245 than that of the no-cultivation control and was greatest in the one-year interval cultivation

246 regime. Significantly fewer Gemmatimonadetes were observed in the one-year interval

247 cultivation regime than in the other sample groups.

248 The LEfSe analysis was used to identify the specific bacterial groups in the soil from

249 forestland with the cultivation regimes and in the no-cultivation control. Major differences were

250 observed in the bacterial groups among the samples. Notably, Acidobacteria was the most

251 common group in the soil with cultivation (Fig. 1b-e). The most frequently observed differences

252 were between the one-year interval cultivation regime and the no-cultivation control (Table S3).

\section{Bacterial $\alpha$-diversity}

254 Before performing the $\alpha$-diversity analysis, the OTU abundance data were normalized with a

255 cutoff value of 59,458. In all samples, the Good's coverage values reached 0.98 (Table S1),

256 indicating that the normalised sequencing data was sufficient to capture the bacterial diversity.

257 The Shannon and Simpson indexes were calculated to evaluate the bacterial diversity (Table S1),

258 and no significant difference was observed among the five grids $(p=0.05)$, even though slightly

259 lower Shannon and Simpson values were observed in the forestlands with cultivation than in the

260 no-cultivation control.

261 OTU-level bacterial $\beta$-diversity analysis

262 The PCA of the bacterial community construction in different samples is shown in Fig. 2a. The 
263 five treatments were clearly distinguished in the PCA. The first two principal components, PC1

264 and PC2, best reflected the differences between these treatments and represented variations of

$26512.35 \%$ and $10.04 \%$ in the bacterial community, respectively. Within the PC1 axis, the one-year

266 interval cultivation regime was distinct from the other regimes. Within the PC2 axis, the no-

267 cultivation control was distinct. Similarly, the weighted Unifrac-based analysis of PCoA and

268 NMDS (Figure S1) and unweighted Unifrac-based analysis of PCoA and NMDS (Figure S2) all

269 showed that the one-year interval cultivation regime was distinct from the other regimes. These

270 data indicated that the bacterial community composition in the one-year interval cultivation

271 regime was relatively distinct from other regimes. However, significant differences in the

272 bacterial community composition were not found between the no-cultivation control and the one-

273 year interval cultivation regime via the AMOVA $(\mathrm{Fs}=4.05, P=0.074)$, the ANOSIM $(\mathrm{R}=1, P$

$274=0.1)$ or the ADONIS $(\mathrm{R} 2=0.52, P=0.1)($ Table S4).

275 The VIF analysis suggested that the soil field capacity, $\mathrm{pH}$, organic matter, total phosphorus,

276 alkaline hydrolysable nitrogen were the uncorrelated edaphic factors in the CCA that could

277 represent the relationship between soil physicochemical properties and bacterial community

278 composition. Based on this model, a total of $60.39 \%$ of the variance was explained by CCA1

279 (24.46\%) and CCA2 (19.49\%), which were the first two constrained axes of the CCA (Fig. 2b).

280 The CCA suggested that the organic matter, total phosphorus, and alkaline hydrolysable nitrogen

281 were the determinants among the edaphic factors. The correlation analysis showed that only

282 organic matter was significantly associated with the soil bacterial composition $(\mathrm{r}=-0.579, P=$ 
$2830.024)$ and the Shannon index $(\mathrm{r}=-0.571, P=0.026)$.

\section{Discussion}

285 Effects of cultivating S. rugosoannulata under nursery stock shade on soil properties

286 Recently, growing S. rugosoannulata under nursery stock shade has been considered a win-win 287 agricultural practice that can improve the quality of nursery stock soil in China. In this study,

288 higher organic matter and available phosphorus content were observed in forestlands with

289 cultivation of S. rugosoannulata compared with the no-cultivation control. However, other soil

290 nutrients did not increase consistently in the forestlands with cultivation; some significantly

291 decreased (Table 2). These results were unexpected because a positive correlation has been

292 observed between the organic matter content and soil fertility (Sadikhani et al. 2014). However,

293 the acute angles between the arrow line representing organic matter content and the arrow lines

294 representing other nutrients in the CCA (TN, TP, AN, AP and AK; Fig. 2b) indicate that organic

295 matter content was positively correlated with the other nutrients in this study also. These results

296 are consistent with those of other studies (Sihi et al. 2017; Zhou et al. 2017).

297 Cultivation in temperate climates usually results in a significant loss of mineralized organic

$298 \mathrm{~N}$ in soil (Tiessen et al. 1994). Although farming S. rugosoannulata in forestland is a type of

299 agricultural practice, it is distinct from traditional crop cultivation. The decrease in alkaline

300 hydrolysable nitrogen content in forestland under cultivation (except for the one-year interval

301 cultivation regime) indicated that the following cultivation regimes resulted in nitrogen loss:

302 fallow for 1 year after prior cultivation regime (Y010), two years of continuous cultivation 
303 regime (Y011) and current-year cultivation regime (Y001). The one-year interval cultivation

304 regime (Y101) effectively suppressed the nitrogen loss and significantly increased the alkaline

305 hydrolysable nitrogen content. In addition, the one-year interval cultivation regime performed

306 well in maintaining soil fertility and had the highest soil nutrient content (Table 2). In contrast,

307 the two years of continuous cultivation regime resulted in a loss of soil nutrients with a

308 significant decrease in total phosphorus, alkaline hydrolysable nitrogen, and available potassium

309 content (Table 2). The current-year cultivation regime resulted in a significant decrease in total

310 nitrogen and alkaline hydrolysable nitrogen content.

311 Soil use and management, such as less intensive management, can cause the loss of

312 phosphorus (Leinweber et al. 1999). Herein, total phosphorus loss was found in the fallow for

313 one year after prior cultivation regime, two years of continuous cultivation regime, and current-

314 year cultivation regime. This loss may have resulted from the use of a large amount of water

315 during the fruiting stage of S. rugosoannulata. In contrast, a significant increase in total

316 phosphorus was observed in the one-year interval cultivation regime, indicating that the amount

317 of phosphorus increase was greater than the amount of phosphorus lost in the one-year interval

318 cultivation regime. We hypothesize that spent mushroom compost left after the harvesting of

319 fruiting bodies would add a certain amount of macronutrients like nitrogen, phosphorous and

320 potassium (NPK) (Kim et al. 2011). However, this hypothesis needs to be further tested in the

321 future.

322 It has been suggested a higher organic matter content may lower the soil pH (Hodes 1996) 
323 and increase the water content at field capacity (Hudson 1994; Tale and Ingole 2015).

324 Inconsistent with this, the two years of continuous cultivation regime and the current-year

325 cultivation regime showed an increase of organic matter content, together with a decrease in the

326 field capacity and an increase in the $\mathrm{pH}$. The decreased field capacity may be related to

327 disturbances from farming practices that disrupt the aggregates in the soil structure (Dong 2017),

328 whereas the increased $\mathrm{pH}$ may have resulted from the application of quicklime (Moir and Moot

3292010 ) on the soil surface before S. rugosoannulata cultivation.

330 Effects of cultivating S. rugosoannulata under nursery stock shade on the soil bacterial

331 community composition

332 Using high-throughput sequencing analyses, we observed a consistently higher abundance of

333 Acidobacteria and a consistently lower abundance of Actinobacteria and Firmicutes in the

334 forestlands with cultivation (Table S1). However, reports (Ramirez et al. 2012; Zhou et al. 2017)

335 showed that the abundance of Acidobacteria was reduced with increased nutrient inputs because

336 of the oligotrophic properties of these organisms, and the abundance of Actinobacteria and

337 Firmicutes was increased with increased nutrient inputs because of the copiotrophic properties of

338 these organisms. These inconsistencies may be ascribed to the increased organic matter in

339 forestlands with cultivation that creates an oligotrophic soil environment due to its ability to

340 slowly release nutrients (Tiessen et al. 1994). In addition, we observed a consistently increased

341 abundance of Planctomycetes and Bacteroidetes and a consistently reduced abundance of

342 Chloroflexi and Nitrospirae in our study (Table S2). The further study is needed to reveal the 
343 underlying mechanisms for this phenomenon.

344 Interactions between soil fungi and bacteria are common in nature. For example, fungus-

345 released compounds may impact bacterial selection (Warmink et al. 2009; Nazir et al. 2010).

346 During the cultivation cycle of $S$. rugosoannulata, high-density hyphae are observed in the

347 culture substrate for long periods and are even found in the spent mushroom compost.

348 Additionally, the soil contains a considerable amount of hyphae. Therefore, the changes in

349 bacterial communities in the soil after the incorporation of spent mushroom compost would be

350 consistent with changes in bacterial communities in soil environments that surround the dense

351 fungal hyphae, such as soil microhabitats, i.e. hyphospheres or mycospheres (Johansson et al.

352 2004; Nazir et al. 2010), that more or less are densely permeated by the fungal hyphae. In our

353 study, a decrease in bacterial diversity was found in forestlands with cultivation (Table S1),

354 which was consistent with reports showing that the bacterial community diversity is lower than

355 that of bulk soil (Warmink et al. 2009; Halsey et al. 2016). Additionally, the selection of bacteria

356 by the hyphae of $S$. rugosoannulata may represent a factor that contributes to the emergence of

357 specific bacterial groups, such as Acidobacteria and Subgroup_6 which also belongs to

358 Acidobacteria in forestlands (Fig. 1b-e). However, it is possible that spent mushroom compost

359 could be more influential on the soil nutrients and bacterial communities because the hyphae of

360 the wine-cap Stropharia disappear along with the deposition of spent mushroom compost (data

361 not published). Further study is needed to understand the impacts of spent mushroom compost

362 and fungal hyphae on soil texture and microbial communities. 


\section{Conclusion}

364 Overall, the increased soil contents of organic matter and available phosphorus and the changes

365 in soil bacterial community composition and diversity in the forestland soil with cultivation

366 suggest that $S$. rugosoannulata cultivation changed the nursery stock soil properties. Given the

367 positive effects on soil physical and chemical properties of organic matter, the highest contents

368 of soil organic matter in the one-year interval cultivation regime suggested that this regime is

369 most appropriate for forestland soils. In addition, this research suggests that (1) organic matter

370 content is the dominant factor affecting soil bacterial community composition, and (2) the spent

371 mushroom compost after harvesting the fruiting bodies of $S$. rugosoannulata is important for

372 improving both soil nutrient content and soil bacterial community composition and diversity, due

373 to the more abundant organic matter and hyphae of S. rugosoannulata.

\section{Acknowledgements}

375 We acknowledge Zhen Liu, Shengming Song from Shandong Agricultural University, China for

376 assisting in the measurement of microbial biomass carbon and chemical properties. We

377 acknowledge Lemei Cao, Haoyu Liu, Lijun Li, and Nianzhao Wang et al. from the college

378 students practice innovation projects of Shandong Agricultural University, China for their help in

379 the measurement of soil physicochemical properties. We also acknowledge the reviewers of this

380 paper for their nice comments.

\section{References}

382 Anderson, M.J. (2001) A new method for non-parametric multivariate analysis of variance. 
Austral ecology 26(1), 32-46.

384 Algina, J. and Keselman, H.J. (1999) Comparing squared multiple correlation coefficients:

385 Examination of a confidence interval and a test significance. Psychological Methods 4(1),

$386 \quad 76-83$.

387 Asnicar, F., Weingart, G., Tickle, T.L., Huttenhower, C. and Segata, N. (2015) Compact

388 graphical representation of phylogenetic data and metadata with GraPhlAn. PeerJ 3, e1029.

389 Benjamini, Y. and Hochberg, Y. (1995) Controlling the false discovery rate: a practical and

$390 \quad$ powerful approach to multiple testing. Journal of the Royal Statistical Society 57(1), 289-

$391 \quad 300$.

392 Bokulich, N.A., Subramanian, S., Faith, J.J., Gevers, D., Gordon, J.I., Knight, R., Mills, D.A.

393 and Caporaso, J.G. (2013) Quality-filtering vastly improves diversity estimates from

$394 \quad$ Illumina amplicon sequencing. Nature Methods 10(1), 57.

395 Bonenfant-Magné, M., Magné, C. and Lemoine, C. (2000) Préparation d'un substrat de culture

396 pour le strophaire (Stropharia rugoso-annulata) par trempage de résidus ligno-cellulosiques

397 agricoles. Canadian Journal of Botany 78(2), 175-180. In French

398 Bremner, J.M. (1965) Total nitrogen. In: Black CA, Evans DD, Ensminger LE, White JL, Clark

399 FE, Dinauer RC (eds) Methods ofsoil analysis part 2-Chemical and microbiological

400 properties number 9 in the aeries agronomy. American Society of Agronomy, Madison, pp

$401 \quad 1149-1178$.

402 Bruhn, J.N., Abright, N. and Mihail, J.D. (2010) Forest farming of wine-cap Stropharia 
mushrooms. Agroforest Syst 79(2), 267-275.

404 Carson, P.L. (1980) Recommended potassium test. In: Dahnke WC (ed) Recommended chemical soil test procedures for the north central region, Bulletin 499. North Dakota Agricultural Experiment Station, Fargo, pp 17-18

407

408

409

410

411

412

413

414

415

416

417

418

419

420

421

422
Caporaso, J.G., Kuczynski, J., Stombaugh, J., Bittinger, K., Bushman, F.D., Costello, E.K., Fierer, N., Peña, A.G., Goodrich, J.K., Gordon, J.I., Huttley, G.A., Kelley, S.T., Knights, D., Koenig, J.E., Ley, R.E., Lozupone, C.A., McDonald, D., Muegge, B.D., Pirrung, M., Reeder, J., Sevinsky, J.R., Turnbaugh, P.J., Walters, W.A., Widmann, J., Yatsunenko, T., Zaneveld, J. and Knight, R. (2010) QIIME allows analysis of high-throughput community sequencing data. Nature methods 7(5), 335.

Chadwick, D., Wei, J., Yan'an, T., Guanghui, Y., Qirong, S. and Qing, C. (2015) Improving manure nutrient management towards sustainable agricultural intensification in China. Agriculture, Ecosystems \& Environment 209, 34-46.

Ciavatta, C., Govi, M., Antisari, L.V. and Sequi, P. (1991) Determination of organic carbon in aqueous extracts of soils and fertilizers. Communications in Soil Science and Plant Analysis 22, 795-807.

Clarke, K.R. (1993) Non-parametric multivariate analyses of changes in community structure. Australian journal of ecology 18(1), 117-143.

Conyers, M.K., Tang, C., Poile, G.J., Liu, D.L., Chen, D. and Nuruzzaman, Z. (2011) A combination of biological activity and the nitrate form of nitrogen can be used to ameliorate 
subsurface soil acidity under dryland wheat farming. Plant and soil 348(1-2), 155-166.

424 CUCEDH (cornell university cooperative extension and department of horticulture). (2013)

$425 \quad$ Method for Cultivating Stropharia Mushrooms.

426

https://blogs.cornell.edu/mushrooms/files/2013/06/Stropharia-21lckcx.pdf

427 Dissanayake, D.M.P.D. and Rajapaksha, R.M.C.P. (2013) Accumilation of Nitrate in Selective

428 Crops and Well Water in Kalpitiya as Affected by Chemical Fertilizer Inputs.

429 http://dlib.pdn.ac.lk/bitstream/1/3883/1/D.M.P.D.Dissanayaka.pdf

430 Domondon, D.L. and Poppe, J. (2000) Fruit optimization with wastes used for outdoor

431 cultivation of king stropharia. In: Van Griensven LJLD (ed) Science and cultivation of

432 edible fungi, vol 2. Balkema, Rotterdam, pp. 909-918.

433 Domondon, D.L., He, W., Kimpe, N.D., Höfte, M. and Poppe, J. (2004) $\beta$-adenosine, a bioactive 434 compound in grass chaff stimulating mushroom production. Phytochemistry 65(2), 181$435 \quad 187$.

436 Dong, Z. (2017) Experimental study on soil compaction by simulated agricultural machinery.

437 Journal of Anhui Agri. Sci. 45(21), 117-119.

438 Duan, X., Xie, Y., Liu, G., Gao, X. and Lu, H. (2010) Field capacity in black soil region, 439 northeast china. Chinese Geographical Science 20(5), 406-413.

440 Edgar, R.C., Haas, B.J., Clemente, J.C., Quince, C. and Knight, R. (2011) Uchime improves

441 sensitivity and speed of chimera detection. Bioinformatics 27(16), 2194-2200.

442 Edgar, R.C. (2013) UPARSE: highly accurate OTU sequences from microbial amplicon reads. 
Nature methods 10(10), 996-998.

444 Edgar R.C. (2004) MUSCLE: multiple sequence alignment with high accuracy and high$445 \quad$ throughput. Nucleic acids research 32(5), 1792-1797.

446 Excoffier, L., Smouse, P.E. and Quattro, J.M. (1992) Analysis of molecular variance inferred

447 from metric distances among DNA haplotypes: application to human mitochondrial DNA

$448 \quad$ restriction data. Genetics $\mathbf{1 3 1}, 479-491$.

449 Geng, J., Chen, J., Sun, Y., Zheng, W., Tian, X., Yang, Y., Li, C. and Zhang, M. (2016)

$450 \quad$ Controlled release urea improved nitrogen use efficiency and yield of wheat and corn.

451 Agronomy Journal 108(4), 1666-1673.

452 Gong, S., Zhao, S.F., Nie, Y., Liu, S.C., Zhang, X.T. and Jiang, S.X. (2016) Economic benifits of 453 Stropharia rugosoannulata under different cultivation methods and conditions. Edible Fungi of China 35(4), 35-38. In Chinese

455 Gross, J. (2003) Variance inflation factors. R News 3(1), 13-15.

456 Haas, B.J., Gevers, D., Earl, A.M., Feldgarden, M., Ward, D.V., Giannoukos, G., Ciulla, D.,

457 Tabbaa, D., Highlander, S.K., Sodergren, E., Methé, B., DeSantis, T.Z., The Human

458 Microbiome Consortium, Petrosino, J.F., Knight, R. and Birren, B.W. (2011) Chimeric 16S rRNA sequence formation and detection in Sanger and 454-pyrosequenced PCR amplicons.

$460 \quad$ Genome Research 21(3), 494-504.

461 Halsey, J.A., De, C.P.E.S.M. and Andreote, F.D. (2016) Bacterial selection by mycospheres of 462 atlantic rainforest mushrooms. Antonie Van Leeuwenhoek 109(10), 1353-1365. 
463 Hawksworth, D.L., Kirk, P.M., Sutton, B.C. and Pegler, D.N. (1996) Dictionary of the fungi VIII. $464 \quad$ CABI.

465 Hodes, S.C. (1996) Soil fertility basics: N.C. certified crop advisor training. Soil Science 466 Extension, North Carolina State University, 75.

467 Hudson, B.D. (1994) Soil organic matter and available water capacity. Journal of Soil and Water $468 \quad$ Conservation 49(2), 189-194.

469 Jining Soil and Fertilizer Workstation. (1990) The Soil of Jining City. Jinan: Shandong $470 \quad$ Cartographic Publishing House. pp. 80-100. In Chinese

471 Jackson M.L. (1958) Soil chemical analysis. Prentice-Hall, Inc, Englewood Cliffs, pp 111-133.

472 Johansson, J.F., Paul, L.R. and Finlay, R.D. (2004). Microbial interactions in the 473 mycorrhizosphere and their significance for sustainable agriculture. FEMS microbiology 474 ecology 48(1), 1-13.

475 Jonathan, S.G., Lawal, M.M. and Oyetunji, O.J. (2011) Effect of spent mushroom compost of 476 Pleurotus pulmonarius on growth performance of four Nigerian vegetables. Mycobiology $477 \quad 39(3), 164-169$.

478 Kim, Y.L., Cho, W.M., Hong, S.K., Oh Y.K. and Kwak, W.S. (2011) Yield Nutrient characteristics, Ruminal Solubility and Degradability of Spent mushroom (Agaricus bisporus) substrate for Ruminants. Asian-Aust. J. Anim. Sci. 24(11): 1560-1560.

481 Kadiri, M. and Mustapha, Y. (2010) The use of spent mushroom substrate of L. subnudus Berk as a soil condition for vegetables. Bayero Journal of Pure and Applied Sciences 3(2), 16- 
Lane, D.J. (1991) 16S/23S rRNA sequencing. In: Nucleic acid techniques in bacterial systematics. Stackebrandt, E., and Goodfellow, M., eds., John Wiley and Sons, New York, NY, pp. 115-175.

Lê, S., Josse, J. and Husson, F. (2008) Factominer: an r package for multivariate analysis. Journal of Statistical Software 25(1), 1-18.

Li, X., Wu, Y., Lin, X., Zhang, J. and Zeng, J. (2012) Dissipation of polycyclic aromatic hydrocarbons (PAHs) in soil microcosms amended with mushroom cultivation substrate. Soil Biology and Biochemistry 47, 191-197.

Leinweber, P., Meissner, R., Eckhardt, K.U. and Seeger, J. (1999) Management effects on forms 493 of phosphorus in soil and leaching losses. European Journal of Soil Science 50(3), 413-424.

Lozupone, C. and Knight, R. (2005). UniFrac: a new phylogenetic method for comparing microbial communities. Appl. Environ. Microbiol. 71, 8228-8235. doi: 10.1128/AEM.71.12.8228-8235.2005

Lu, W., Yu, S., Ma, Y. and Huang, H. (2018) Integrated economic and environmental analysis of agricultural straw reuse in edible fungi industry. PeerJ 6, e4624.Magoč, T. and Salzberg, S.L. (2011) Flash: fast length adjustment of short reads to improve genome assemblies. Bioinformatics 27(21), 2957-2963. 

ands Stropharia. Mycologia 14(3), 121-142.

Nazir, R., Warmink, J.A., Boersma, H. and Elsas, J.D.V. (2010) Mechanisms that promote bacterial fitness in fungal-affected soil microhabitats. Fems Microbiology Ecology 71(2), 169-185.

Oksanen, J., Kindt, R., Legendre, P., O’Hara, B., Stevens, M.H.H., Oksanen, M.J. and Suggests, M.A.S.S. (2007) The vegan package. Community ecology package 10, 631-637.

Olsen, S.R. (1954) Estimation of available phosphorus in soils by extraction with sodium bicarbonate. Miscellaneous Paper Institute for Agricultural Research Samaru.

512 Peck, J. (2010) Multivariate analysis for community ecologists: step-by-step using PC-ORD.

513 MjM Software, Gleneden Beach.

514 Quast, C., Pruesse, E., Yilmaz, P., Gerken, J., Schweer, T., Yarza, P., Peplies, J. and Glöckner,

515 F.O. (2012). The SILVA ribosomal RNA gene database project: improved data processing

516 and web-based tools. Nucleic acids research 41(D1), D590-D596.

517 Ramirez, K.S., Craine, J.M. and Noah, F. (2012) Consistent effects of nitrogen amendments on 518 soil microbial communities and processes across biomes. Global Change Biol 18(6), 19181927.

Rao, C.R. (1995) A review of canonical coordinates and an alternative to correspondence analysis using Hellinger distance. Qüestiió: quaderns d'estadística i investigació operativa 19(1): 23-63. 
523 Sadikhani, M.R., Sohrabi, A. and Fard, F.G. (2014) Soil organic Carbon and estimation

524 difficulties. International Journal of Advanced Life Sciences 7(3), 375-383.

525 Segata, N., Izard, J., Waldron, L., Gevers, D., Miropolsky, L., Garrett, W.S. and Huttenhower, C.

526 (2011) Metagenomic biomarker discovery and explanation. Genome Biol 12(6), R60.

527 Sihi, D., Dari, B., Sharma, D.K., Pathak, H., Nain, L. and Sharma, O.P. (2017) Evaluation of soil

528 health in organic vs. conventional farming of basmati rice in North India. Journal of Plant

$529 \quad$ Nutrition and Soil Science 180(3), 389-406.

530 Socolow, R.H. (1999) Nitrogen management and the future of food: Lessons from the

531 management of energy and carbon. Proceedings of the National Academy of Sciences of the

$532 \quad$ United States of America, 96(11), 6001-6008.

533 Sun, J., Zhang, Q., Zhou, J. and Wei, Q. (2014) Illumina amplicon sequencing of 16s rrna tag

534 reveals bacterial community development in the rhizosphere of apple nurseries at a replant

535 disease site and a new planting site. Plos One 9(10), e111744.

536 Tale, K.S. and Ingole, S. (2015) A review on role of physico-chemical properties in soil quality.

537 Chem. Sci. Rev. Lett 4(13), 57-66.

538 Tiessen, H., Cuevas, E. and Chacon, P. (1994) The role of soil organic matter in sustaining soil

539 fertility. Nature 371(6500), 783-785.

540 Turner, S., Pryer, K.M., Miao, V. P. and Palmer, J.D. (1999) Investigating deep phylogenetic

541 relationships among cyanobacteria and plastids by small subunit rRNA sequence analysis 1.

$542 \quad$ Journal of Eukaryotic Microbiology 46(4), 327-338. 
543 Uzun, I (2004) Use of spent mushroom compost in sustainable fruit production. Journal of Fruit $544 \quad$ and Ornamental Plant Research 12, 157-165.

545 Wang, F.H., Wang, X.Q. and Sayre, K. (2004) Comparison of conventional, flood irrigated, flat 546 planting with furrow irrigated, raised bed planting for winter wheat in China. Field Crops $547 \quad$ Research 87(1), 35-42.

548 Wang, Q., Garrity, G.M., Tiedje, J.M. and Cole, J.R. (2007) Naïve bayesian classifier for rapid 549 assignment of rRNA sequences into the new bacterial taxonomy. Applied \& Environmental $550 \quad$ Microbiology 73(16), 5261-5267.

551 Warmink, J.A., Nazir, R., and Elsas, J.D. (2009) Universal and species- specific bacterial 552 'fungiphiles' in the mycospheres of different basidiomycetous fungi. Environ Microbiol 553 11(2), 300-312.

554 Wickham, H. (2010) ggplot2: elegant graphics for data analysis. Journal of statistical software 35(1), 65-88.

Xiong, Y., Xia, H., Li, Z., Cai, X. and Fu, S. (2008) Impacts of litter and understory removal on soil properties in a subtropical acacia mangium, plantation in china. Plant and Soil 304(12), 179-188.

Yang, F.J., Zhang, C.L., Xie, C. and Li, W.W. (2015) Study on inter-planting cultivation

560 techniques of Stropharia rugoannulata and benefi analysis under the forest in the highland 561 tropical. Modern Agricultural Sciences and Technology (1), 96-97. In Chinese

562 Zeng, J. (2013) Interplanting technology of Stropharia rugosoannulata under fruit trees. Fujian 
563 Science \& Technology of Tropical Crops 38(3):49-50. In Chinese

564 Zheng, W., Sui, C., Liu, Z., Geng, J., Tian, X., Yang, X., Li, C. and Zhang, M. (2016) Long-term

565 effects of controlled-release urea on crop yields and soil fertility under wheat-corn double

566 cropping systems. Agronomy Journal 108(4), 1703-1716.

567 Zhou, J., Bruns, M.A. and Tiedje, J.M. (1996) Dna recovery from soils of diverse composition.

568 Applied and Environmental Microbiology 62(2), 316-322.

569 Zhou, J., Jiang, X., Wei, D., Zhao, B., Ma, M., Chen, S., Cao, F., Shen, D., Guan, D. and Li, J.

570 (2017) Consistent effects of nitrogen fertilization on soil bacterial communities in black

$571 \quad$ soils for two crop seasons in China. Scientific reports 7(1), 3267. 


\section{Table $\mathbf{1}$ (on next page)}

Cultivation year of each grid. 
1 Table 1 Cultivation year of each grid.

\begin{tabular}{lllll}
$\begin{array}{llll}\text { Sample plot } \\
\text { groups }\end{array}$ & \multicolumn{2}{l}{ Cultivation year } & Description in the text \\
\cline { 2 - 4 } 2013 & 0 & 2014 & 2015 & \\
\hline Y000 & 0 & 0 & 0 & $\begin{array}{l}\text { no-cultivation control } \\
\text { fallow for one year after prior } \\
\text { cultivation regime }\end{array}$ \\
Y011 & 0 & 1 & 0 & $\begin{array}{l}\text { two years of continuous } \\
\text { cultivation regime }\end{array}$ \\
Y001 & 0 & 1 & 1 & $\begin{array}{l}\text { current-year cultivation regime } \\
\text { one-year interval cultivation } \\
\text { Y101 }\end{array}$ \\
1 & 0 & 1 & 1 & regime
\end{tabular}

2 The number " 1 " in the cultivated year column indicates that the cultivation occurred in the corresponding 3 year, whereas " 0 " indicates that no cultivation was performed in the corresponding year. 
Table 2 (on next page)

Soil properties according to different grids. 
1 Table 2 Soil properties according to different grids.

\begin{tabular}{lllllllll}
\hline $\begin{array}{l}\text { Sample } \\
\text { plot } \\
\text { groups }\end{array}$ & $\mathrm{FC}$ & $\mathrm{pH}$ & $\begin{array}{l}\mathrm{OM} \\
(\mathrm{g} / \mathrm{Kg})\end{array}$ & $\begin{array}{l}\mathrm{TN} \\
(\mathrm{g} / \mathrm{Kg})\end{array}$ & $\begin{array}{l}\mathrm{TP} \\
(\mathrm{g} / \mathrm{Kg})\end{array}$ & $\begin{array}{l}\mathrm{AN} \\
(\mathrm{mg} / \mathrm{Kg})\end{array}$ & $\begin{array}{l}\mathrm{AP} \\
(\mathrm{mg} / \mathrm{Kg})\end{array}$ & $\begin{array}{l}\mathrm{AK} \\
(\mathrm{mg} / \mathrm{Kg})\end{array}$ \\
\hline Y000 & $18.86 \pm 0$. & $6.88 \pm 0.0$ & $\mathbf{8} \pm \mathbf{0 . 0 2 5}$ & $0.44 \pm 0$. & $0.41 \pm 0$. & $67.85 \pm 0.1$ & $\mathbf{3 0 . 5 9} \pm \mathbf{0 . 0}$ & $101.12 \pm 0$. \\
& $029 \mathrm{a}$ & $33 \mathrm{a}$ & $\mathbf{d}$ & $008 \mathrm{c}$ & $005 \mathrm{~b}$ & $66 \mathrm{~b}$ & $\mathbf{0 8 e}$ & $159 \mathrm{~d}$ \\
Y010 & $19.54 \pm 0$. & $6.85 \pm 0.0$ & $9.9 \pm 0.1$ & $0.48 \pm 0$. & $\mathbf{0 . 3 3} \pm \mathbf{0}$. & $39.18 \pm 0.2$ & $40.53 \pm 0.0$ & $119.37 \pm 0$. \\
& $035 \mathrm{a}$ & $48 \mathrm{a}$ & $25 \mathrm{~b}$ & $004 \mathrm{~b}$ & $\mathbf{0 0 2 d}$ & $63 \mathrm{~d}$ & $26 \mathrm{c}$ & $088 \mathrm{~b}$ \\
Y011 & $18.12 \pm 0$. & $6.97 \pm 0.0$ & $8.9 \pm 0.0$ & $0.47 \pm 0$. & $0.36 \pm 0$. & $58.02 \pm 0.1$ & $53.94 \pm 0.1$ & $\mathbf{9 4 . 9 7 \pm 0 . 1}$ \\
& $028 \mathrm{a}$ & $25 \mathrm{a}$ & $3 \mathrm{c}$ & $006 \mathrm{bc}$ & $002 \mathrm{c}$ & $57 \mathrm{c}$ & $91 \mathrm{~b}$ & $\mathbf{7 6 e}$ \\
Y001 & $17.69 \pm 0$. & $6.9 \pm 0.03$ & $10.4 \pm 0$. & $\mathbf{0 . 2 2} \pm \mathbf{0 .}$ & $0.38 \pm 0$. & $\mathbf{3 8 . 1 8} \pm \mathbf{0 . 1}$ & $37.81 \pm 0.0$ & $106.27 \pm 0$. \\
& $025 \mathrm{a}$ & $9 \mathrm{a}$ & $298 \mathrm{~b}$ & $\mathbf{0 0 3 d}$ & $005 \mathrm{~b}$ & $\mathbf{4 6 e}$ & $43 \mathrm{~d}$ & $504 \mathrm{c}$ \\
Y101 & $22.72 \pm 0$. & $6.88 \pm 0.0$ & $\mathbf{2 3 . 4 \pm 0 .}$ & $\mathbf{0 . 9 5} \pm \mathbf{0 .}$ & $\mathbf{0 . 5 7} \pm \mathbf{0 .}$ & $\mathbf{1 0 3 . 1 3} \pm \mathbf{0}$. & $\mathbf{8 8 . 2 9} \pm \mathbf{0 . 0}$ & $\mathbf{1 5 2 . 1} \pm \mathbf{0 . 2}$ \\
& $004 \mathrm{a}$ & $51 \mathrm{a}$ & $\mathbf{2 8 8 a}$ & $\mathbf{0 1 3 a}$ & $\mathbf{0 1 a}$ & $\mathbf{2 2 8 a}$ & $\mathbf{4 8 a}$ & $\mathbf{a}$ \\
\hline
\end{tabular}

2 Values are the average of three replicate soil samples. Values followed by the same letter are not

3 significantly different at $P>0.05$ (ANOVA, Tukey analysis). The significant maximum and minimum

4 values of each soil property among all grids are shown in bold. $F C$, soil field capacity; $p H$, soil $\mathrm{pH} ; O M$,

5 organic matter; $T N$, total nitrogen; $T P$, total phosphorus; $A N$, alkaline hydrolysable nitrogen; $A P$,

6 available phosphorus; $A K$, available potassium. 
Figure 1 (on next page)

Bar chart of bacterial relative abundance at the phylum level and bar chart based on the LDA value.

(A) Bar chart of bacterial relative abundance at the phylum level. Bar chart based on the LDA value, bacterial community groups in comparison pairs with significant differences (LDA score $>4$ ) in abundance are shown. Comparison pairs: (B) Y010/Y000, (C) Y011/Y000, (D) Y001/Y000, (E) Y101/Y000. 


\section{PeerJ}

Y101

Y001

Y011

Y010

Y000

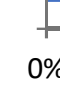

$0 \%$
Proteobacteria
a Planctomycetes
Nitrospirae
Acidobacteria
Bacteroidetes
Chlorobi
Actinobacteria
- Gemmatimonadetes $\square$ Firmicutes
Others
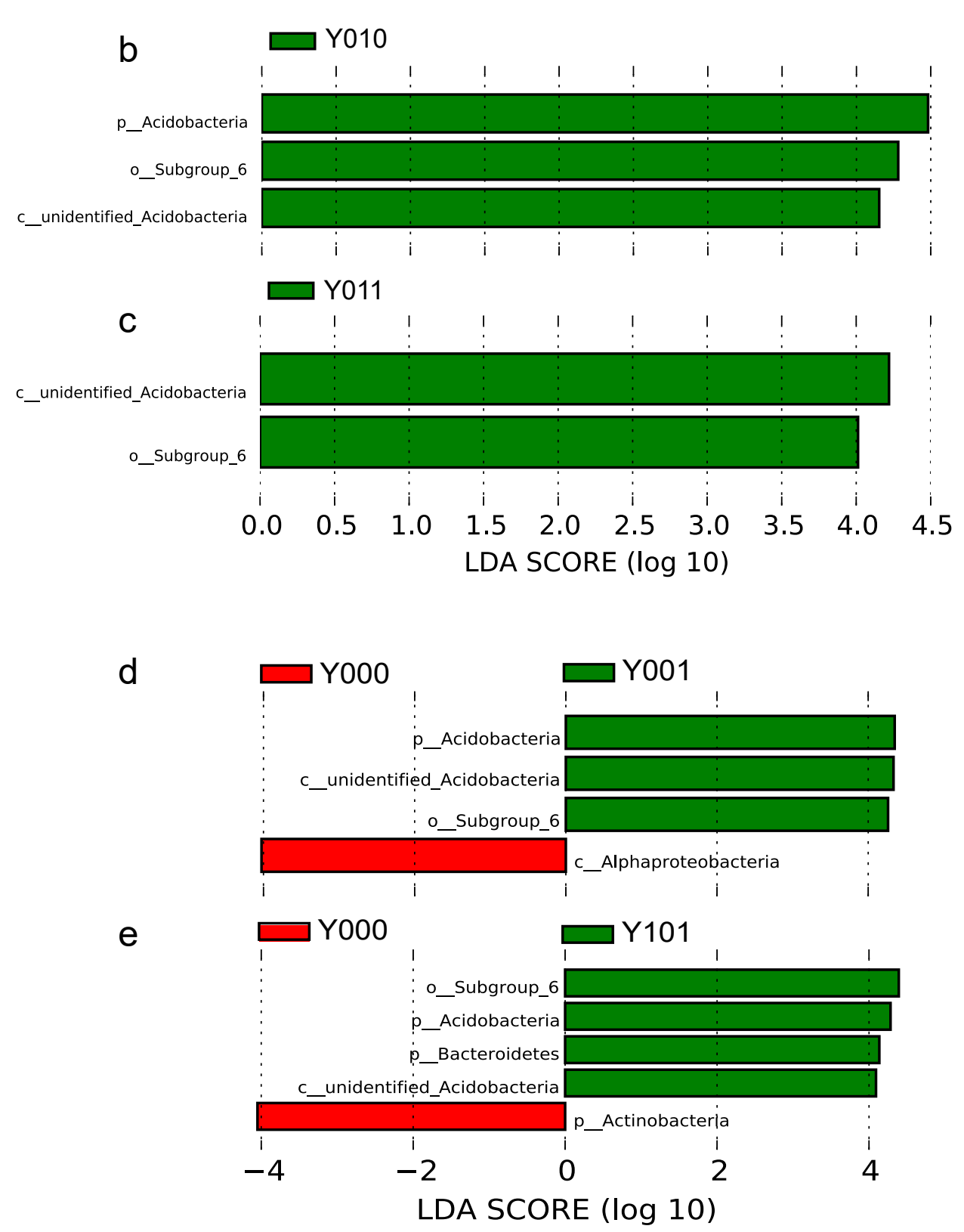


\section{Figure 2 (on next page)}

Principal component analysis (PCA) and canonical correspondence analysis (CCA).

(A) PCA based on OTUs of the bacterial community. (B) CCA based on edaphic factors and the bacterial community composition. Different grids are represented by different colours. Spots with the same colour represent the same grids. Edaphic factors are shown as arrows, and the degree of correlation between one edaphic factor and community/species composition is represented by the length of the arrow. Longer arrows indicate higher correlations. The angle constructed by the arrow and the ordination axes indicates the correlation between the edaphic factors and the ordination axes. A smaller angle indicates a higher correlation. FC, field capacity; OM, organic matter; TN, total nitrogen; TP, total phosphorus; AN, alkaline hydrolysable nitrogen; AP, available phosphorus; and AK, available potassium. Available edaphic factors for the bacterial community composition are shown as *, i.e., having a variance inflation factor (VIF) value of less than 20. 

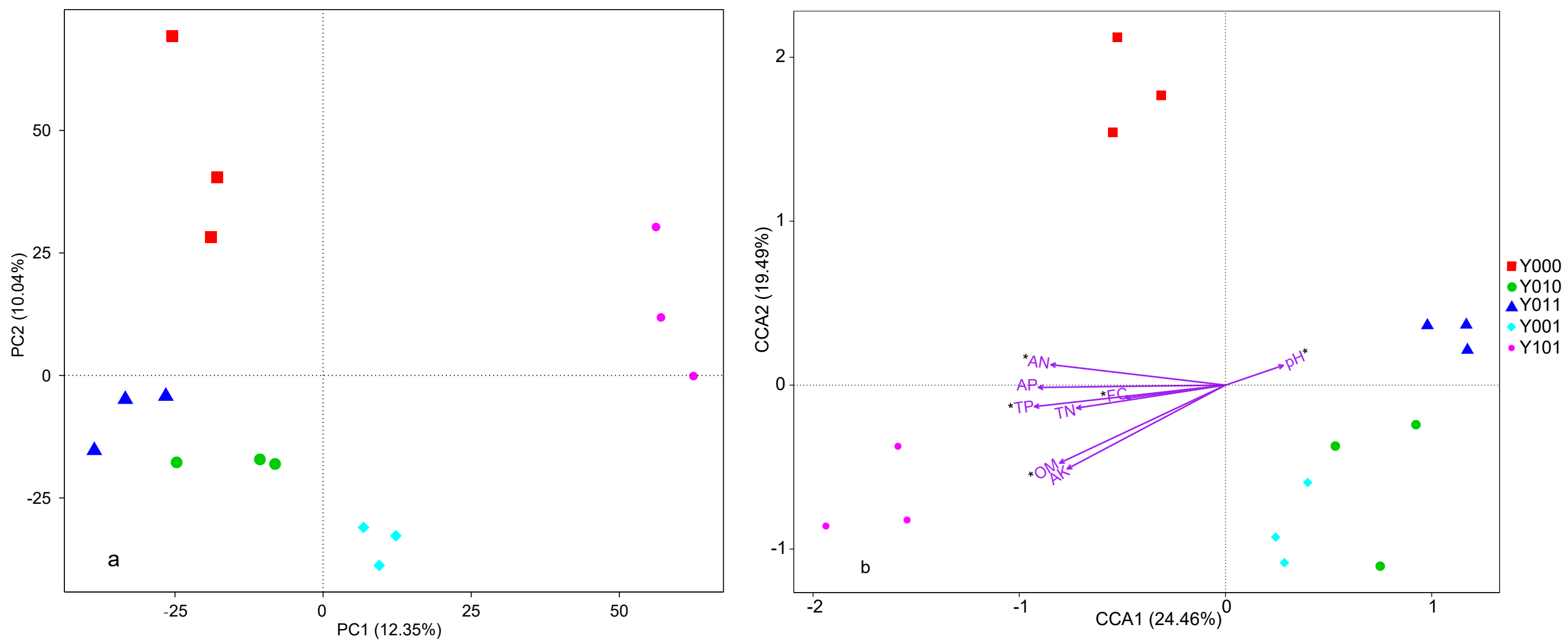